\title{
CONGENITAL DISLOCATION OF THE HIP
}

\section{The Development of a Regional Service}

\author{
Ian G. MacKenzie, Aberdeen, Scotland \\ From the Royal Aberdeen Children's Hospital
}

Hippocrates (460-357 в.C.) was familiar with the crippling effects of untreated congenital dislocation of the hip, but only during the second half of this century has any substantial progress been made in early treatment. This is not really surprising because inadaquately treated and even untreated children may remain free from symptoms until they grow up and have children of their own; they then begin to put on weight and find that they cannot keep up with their housework or their children.

The surgeon who does not keep in touch with his patients until they reach adult life is ignorant of their fate, and understandably happy with his results. Much enthusiasm, ingenuity and technical skill have been spent devising operations for children who are brought to orthopaedic clinics as late walkers or bad walkers, but it is now realised that much of this effort has been wasted, that even excellent early results may not last, and that the problem must be tackled at a much earlier stage. Unstable hips must be treated soon after birth when there is no obvious abnormality. Special techniques are required for diagnosis, and simple treatment for a brief period is successful.

Roser (1879) appreciated that the diagnosis could be made shortly after birth, that reduction occurred if the hips were abducted, and that cure followed if this position was maintained for a few weeks. Putti (1927) emphasised that many excellent results could follow treatment started before the age of one year. Ortolani (1937) described a test to detect dislocation in children from three to nine months of age, but many orthopaedic surgeons were not familiar with his work even twenty years later.

TABLE I

Numbers of Live BirThs Between 1960 AND 1969 AND Their Distribution betWEen Various Hospitals

\begin{tabular}{|cccccc|}
\hline \multicolumn{2}{c}{ Place of birth } & & \multicolumn{2}{c|}{ Live births } \\
& & & Number & Per cent \\
\hline Aberdeen Maternity Hospital & & 28,426 & 37 \\
Other Aberdeen hospitals &. & 14,187 & 18 \\
Peripheral hospitals &. &. & 30,104 & 40 \\
At home &. &. &. & 3,958 & 5 \\
\hline Total &. &. &. & 76,675 & 100 \\
\hline
\end{tabular}

Palmén (1961) started routine examination of the hips of newborn children in Sweden in 1950, and estimated that by 196049 per cent of all children born in Sweden were examined within a few days of birth. Von Rosen (1962) appreciated the value of Palmén's work, and started a similar scheme in Malmö in 1952; he confirmed Roser's belief that splinting unstable hips in abduction for a few weeks resulted in normal joints. His results have been widely publicised and have stimulated similar schemes in other countries. 
Barlow (1962) was the first surgeon to start routine screening of newborn infants in Britain. Other series have been reported by Stanisavljevic (1964) from America; Weissman and Salama (1966) from Israel; and Finlay, Maudsley and Busfield (1967) from London.

\section{PRESENT INVESTIGATION}

In 1960 a new clinic was started in the Royal Aberdeen Children's Hospital, with the object of concentrating the care of all children with congenital dislocation of the hip under one surgical team who would also be responsible for trying to ensure that all children born in the North-Eastern Region of Scotland were examined within a few days of birth. Any infant found to be abnormal would be referred to the clinic for treatment. These children are the basis of this review.

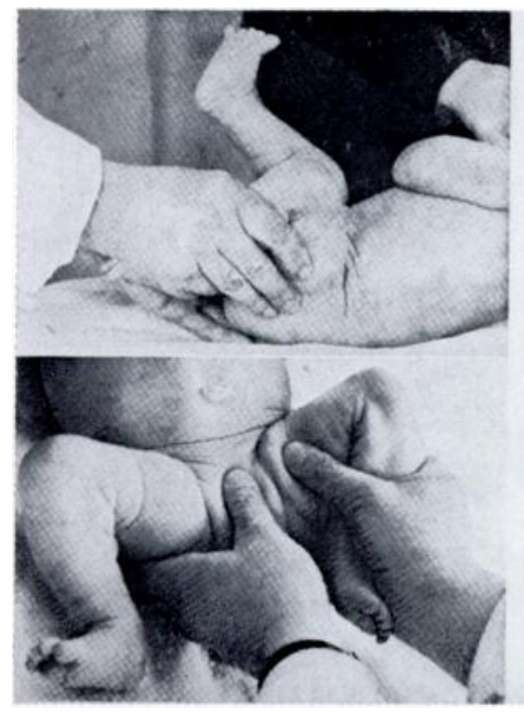

\section{EVERY BABY'S HIPS SHOULD BE EXAMINED}

1. Put baby on its back on a firm surface.

2. It must be relaxed: give it a bottle if needed.

3. Flex hips and knees to $90^{\circ}$ : abduct hips $45^{\circ}$

To examine the Left Hip:

4. Fix pelvis with left hand, thumb on pubis and long finger on sacrum.

5. Fix thigh with right hand, thumb in groin and long finger on graater trochanter.

6. Press forward with long finger of right hand

IF THE FEMORAL HEAD MOVES THERE IS DISLOCATION

Adequate early treatment is always successful. Delay in diagnosis is crippling.

SPECIAL CLINIC R.A.H.S.C. 2 p.m. MONDAY. No Appointment Needed.

Fig. 1

The card sent to all family doctors with the summary of the method of diagnosis.

The population of the region is 479,000 ( 1961 census); the live births number about 8,000 per annum. The families are scattered over a wide area, but the maternity services are centralised and over 90 per cent of children are born in hospital (Table I). Infants born in the city of Aberdeen are now examined by paediatric registrars, and those born in peripheral hospitals or at home, by the family doctor and midwife. All doctors and midwives have been shown the methods of examination; every family doctor has been asked to cooperate, and has been sent a card which outlines the method of examination (Fig. 1). Larger poster versions of the card are displayed in all the peripheral hospitals and a film illustrating examination and treatment is regularly shown to successive generations of medical students, midwives and health visitors.

During the decade 1960-69, 1,671 infants with abnormal hips have been seen at the clinic and followed until they were at least one year old.

Clinical examination-Barlow's (1962) modification of Ortolani's test is used. The baby is placed supine on a firm surface and must be relaxed; it is useless to try to examine a screaming infant. Relaxation can usually be secured by the time-hallowed if unhygienic trick of letting the child suck the mother's finger. The examiner must be quiet and unhurried, and the examining hands must be warm and gentle.

Vol. 54 B, NO. 1, FEBRUARY 1972 
To examine the left hip, the examiner fixes the pelvis with his left thumb on the pubis and his left middle finger on the sacrum. With his right hand he flexes the child's left hip and knee and fixes the femur with is right thumb on the lesser trochanter and his right middle finger on the greater trochanter; the left hip is then abducted and pressure is applied with the examiner's right middle finger. If the hip is dislocated, it will reduce with a palpable and

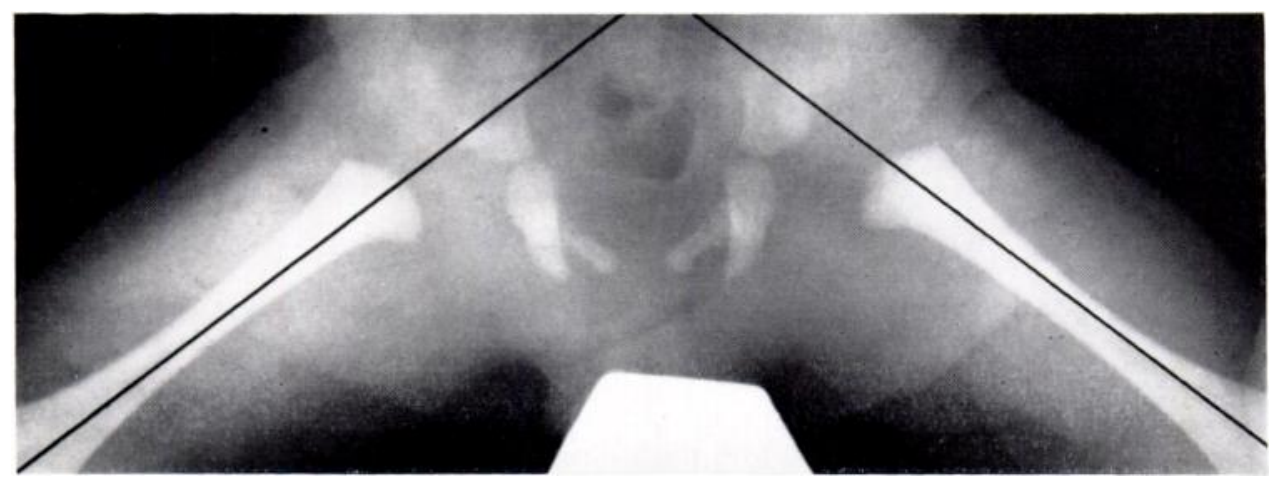

FIG. 2

Andrén-von Rosen view showing dislocation.

sometimes visible jerk. Pressure with the examiner's right thumb will then redislocate the hip or will dislocate an unstable hip that happened to be reduced at the beginning of the examination. If there is no sign of instability, abduction is continued; the hips of a normal newborn infant can be abducted in 90 degrees of flexion until the thighs almost touch the couch. Any limitation of abduction may be significant, and is noted.

Ortolani (1937) described reduction of a dislocated hip occurring during abduction in the flexed position, and being accompanied by a "jerk" or a "jolt". Mistranslation from the Italian has led to the widespread use of the word "click" in the English literature. This word "click" is misleading and should be avoided. Fascial clicks in the region of the hip, and vacuum clicks arising in hip and knee are common in infants, and should not be confused with the jerk of an unstable hip.

TABLE II

Correlation of 241 Andrén-von Rosen Radiographic Findings With the Clinical Findings

\begin{tabular}{|lcccc|}
\hline & \multicolumn{4}{c|}{ Radiographic findings } \\
Clinical findings & Positive radiographs & Negative radiographs \\
& Number & Per cent & Number & Per cent \\
\hline Unstable hips & 75 & 63 & 85 & 70 \\
Stiff hips & 44 & 37 & 37 & 30 \\
\hline Total & 119 & 100 & 122 & 100 \\
\hline
\end{tabular}

Radiographic examination-We agree with Barlow (1968) that radiographic examination is not necessary, and may even be misleading. Andrén and von Rosen (1958) described a special technique which von Rosen thinks is reliable. The child is placed supine and each hip is abducted 45 degrees and rotated medially with the knees extended. An antero-posterior film of the pelvis is taken. In a normal hip the axis of the femur, when projected, crosses the lateral 
margin of the acetabulum; in a dislocated hip the femoral axis crosses the anterior superior iliac spine (Fig. 2).

Smaill (1968) used this technique for two years "without much success". We used it in the first 241 children in this series to try to assess the importance of limitation of abduction of the hip in infants when there was no demonstrable instability. The radiological results were correlated with the clinical findings, and are shown in Table II. Thirty-seven per cent of those with positive radiographs were found to have stiff hips without instability on clinical examination. Limitation of abduction must therefore be treated. On the other hand, 70 per cent of those with negative radiographs had definite clinical instability. A negative radiograph in a child with stiff hips does not exclude dislocation.

Some of these negative results may have been due to faulty positioning. The legs must be abducted so that they subtend a right angle, and they must be rotated medially; this position is difficult to obtain and the positioning should be the responsibility of a doctor and not left to a radiographer. Over-enthusiastic attempts to obtain this unnatural position can fracture an infant's femur.

Outline of treatment-The following scheme has been evolved over the years and found to be reliable. Every infant is examined within a day or two of birth. If there is any doubt about the findings the baby is examined again the following day. The findings are noted, but no treatment is advised at this stage. The condition is explained to the mother; it is important that this should be done in an unhurried, sympathetic and confident manner. A few mothers

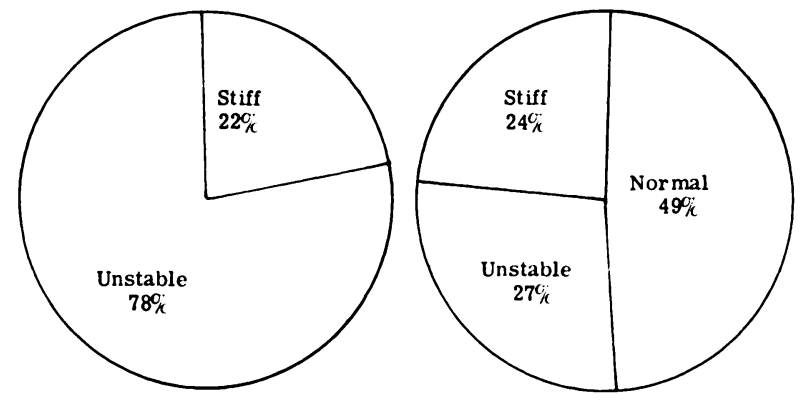

FIG. 3

Fig. 4

Figure 3-Findings at birth. Figure 4-Findings at three weeks.

refuse to accept that there is anything wrong with their babies because they can see nothing wrong. Time spent at this stage in explanation, answering questions, and reassurance, is time well spent. When the child leaves the hospital an appointment is made for it to be seen again at the special children's clinic when it is three weeks old.

Of every 100 children noted to have abnormal hips at birth, seventy-eight are unstable and twenty-two have only limited abduction of the hips (Fig. 3). At their first attendance at the special clinic, ample time is allowed for re-examination of the infant and further explanation and discussion with the mother. Almost half the children are clinically normal at this stage (Fig. 4). These are not treated, but the mother is advised to bring her child back for another clinical and radiographic examination when it is three months old. If at three weeks there is still either instability or limitation of abduction of the hips, a splint is fitted. It is important to fit as large a splint as possible (Fig. 5). The mother is then asked to return when the child is six weeks old. Children at this age grow rapidly, and by six weeks the first splint is usually too small. The child is examined again. More than two-thirds are normal by this time. A larger splint is usually needed and is fitted, and the mother is asked to bring the child back when it is three months old.

VOL. 54 B, NO. 1, FEBRUARY 1972 
At three months all children are examined again, and the first radiograph (a plain anteroposterior film of the pelvis with lower limbs extended and in neutral rotation) is taken. Those who were clinically normal at three weeks, and whose three-month radiographs show femoral

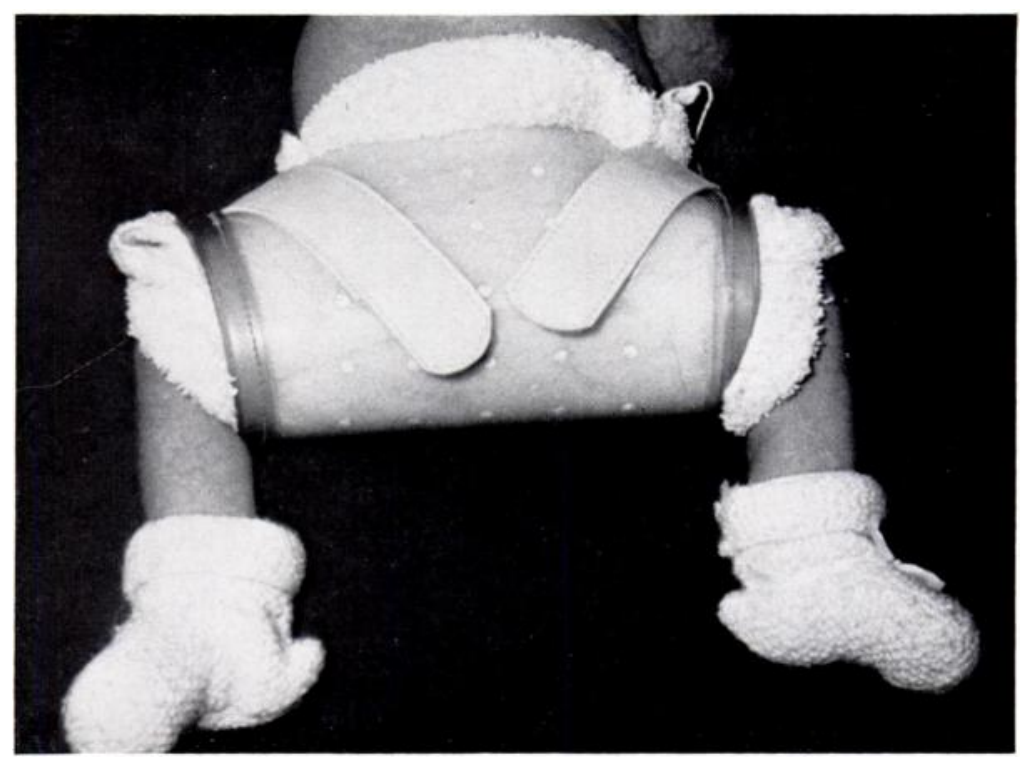

FIG. 5

The method of splintage.

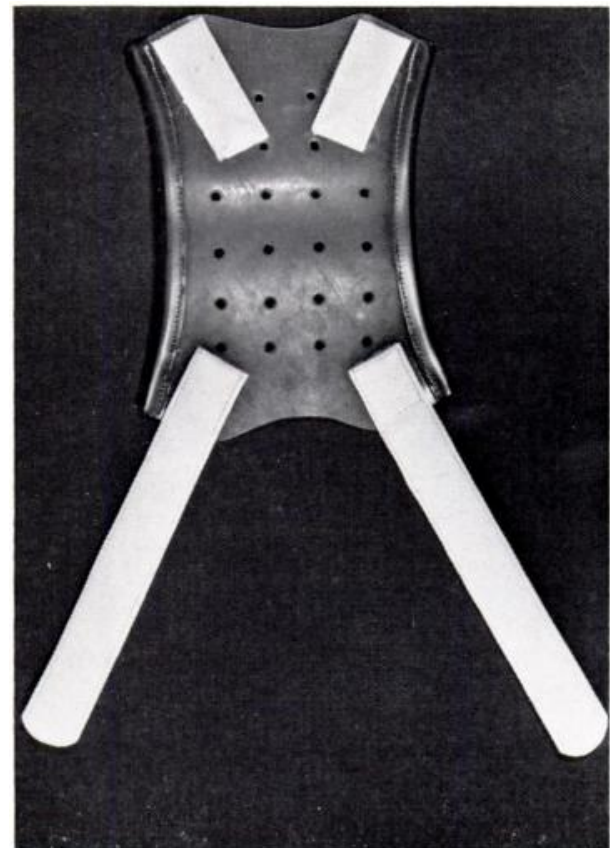

FiG. 6

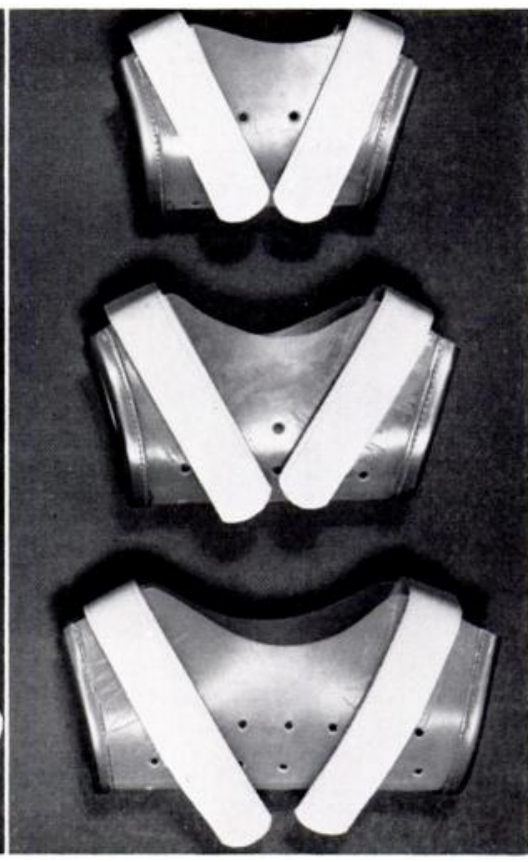

FIG. 7

Figure 6-The Stracathro splint. Figure 7-Various sizes of splint.

epiphyses in normal position, are discharged. It is not wise to discharge children whose femoral epiphyses have not appeared, even though they are apparently clinically normal, and the mothers of these children are asked to bring them back for further radiographs at the age 
of six months. Almost all those who have been splinted from three weeks will be clinically normal at three months. The radiographic findings in these children are noted, the splints are discarded, and the mothers are asked to bring the children back to the clinic at the age of six months. Rarely, there is still some clinical abnormality at three months, and splintage is then continued, but this is most unusual if the splint has been applied at three weeks. Von Rosen (1968) noted that children with hypermobile joints or a strong family history of hip dislocation may need splintage for longer periods.

Further radiographs are taken when the children are six months old: most will show femoral epiphyses in normal position, and these children can be discharged. If the femoral epiphyses are still not present, another radiograph is taken at one year. In exceptional cases a child will have to be followed until it is eighteen months old to be certain that it is normal. The splint-In the early stages of the study we used von Rosen's splint and Barlow's splint but we discontinued them because the mothers found them difficult to manage, and some children developed pressure sores. Barlow (1962) examined each child under treatment at weekly intervals, readjusting the splint at each attendance, and the mothers of his patients were instructed not to interfere with the splints. Such a regime is not applicable to a region like this with a scattered population. A visit to the central hospital may mean a five-hour journey, and weekly visits would impose an intolerable burden on mothers with other young children.

We decided that any splint must be easily applied by the mother and equally easily removed if complications arise, and that it should allow access for washing both splint and child. Begg (1960) devised such a splint, and our supplies are obtained from his workshops at Stracathro Hospital. The splint is made of $\frac{1}{16}$-inch (1.5-millimetre) natural polythene with about twenty holes punched through it to allow ventilation. The outer edge is beaded with half-inch (1-2-centimetre) Vinyl tubing, and it is fastened with two 11-inch (3-centimetre) Velcro straps backed with Vinyl (Fig. 6). The smallest size made is $5 \frac{1}{2}$ inches wide by $8 \frac{1}{2}$ long (14 by 21 centimetres), and further sizes are available at one inch graduations up to $12 \frac{1}{2}$ inches wide by 12 inches long ( 31 by 30 centimetres) (Fig. 7). It is hard wearing and easily washed and dried.*

We have now used this splint in over 2,000 children. One infant was sensitive to the polythene. As with other splints, some infants are fretful for a day or two, but most settle remarkably rapidly. The plastic material, even though perforated, tends to retain moisture in the nappies, and rashes may arise if the nappies are not changed regularly. The mothers are warned about this, and no serious troubles have arisen. No case of failure of treatment was attributable to the splint.

\section{MATERIALS}

The main findings are shown in Table III. A total of 1,671 children have been seen at the clinic during the period under review. Three hundred and four who received no treatment were clinically normal when they first attended, and were naturally not splinted: we initially splinted all children as soon as the diagnosis was made, and the number of spontaneous cures at three weeks would clearly have been much larger if we had from the outset adopted our present policy of not applying splints until the child is three weeks old. Eight hundred and thirteen children had instability of the hips at three weeks, with or without some limitation of abduction; they were splinted. Three hundred and forty-eight had limitation of abduction of the hips at three weeks without clinical signs of instability; these were also splinted. Eightysix children ( 5 per cent of the total) required in-patient operative treatment. This was usually because the diagnosis had been missed at birth, but sometimes because errors of judgement were made at the clinic, and sometimes because the mothers refused our advice and would not allow their children to be splinted.

* The splint is now available through Remploy Ltd., 415 Edgware Road, Cricklewood, London N.W.2, at a cost of $£ 1 \cdot 25$.

VOL. 54 B, NO. 1, FEBRUARY 1972 
Incomplete records-Complete follow-up to one year was possible in 93 per cent of the 1,671 children. The records in the remaining 120 are incomplete for various reasons. There were eight deaths (4.8 per thousand), which compares with an infant mortality rate for the NorthEastern Region of 16.8 per thousand. Three children with severe congenital heart disease died in hospital and the other five died at home. We have no reason to suppose that death in these five was other than from natural causes, but have been disturbed by the recent case of a child brought in dead to the casualty department with multiple injuries caused by the putative father throwing her bodily across the room apparently because she was constantly crying.

TABLE III

SUMmaRY OF FindingS IN THE VARIOUS GROUPS

\begin{tabular}{|c|c|c|c|c|c|}
\hline Findings & Whole series & Unsplinted & $\begin{array}{l}\text { Per cent } \\
\text { Unstable }\end{array}$ & Operation & Stiff \\
\hline . $\quad$. & 39 & 44 & 37 & 15 & 41 \\
\hline .. & 61 & 56 & 63 & 85 & 59 \\
\hline Family history . & 5 & 6 & 5 & 12 & 3 \\
\hline Other defects at birth . & 2 & 1 & 1 & 12 & 1 \\
\hline Breech delivery . & 4 & 3 & 4 & 6 & 2 \\
\hline Caesarean section & 5 & 3 & 6 & 3 & 5 \\
\hline $\begin{array}{l}\text { Epiphyses not showing } \\
\text { at three months. }\end{array}$ & - & 66 & 66 & - & 66 \\
\hline $\begin{array}{l}\text { Epiphyses not showing } \\
\text { at six months }\end{array}$ & - & 11 & 16 & - & 16 \\
\hline Walking at one year . & - & 38 & 45 & - & 44 \\
\hline Abnormal at six weeks & - & - & 13 & - & 16 \\
\hline Hips also stiff . & - & - & 36 & - & - \\
\hline Bilateral dislocation & - & - & 53 & 41 & 84 \\
\hline Left dislocation . & $-\cdots$ & - & 28 & 40 & 12 \\
\hline Right dislocation & - & - & 19 & 19 & 4 \\
\hline Total number. & 1,671 & 304 & 813 & 86 & 348 \\
\hline
\end{tabular}

Thirteen children attended the clinic until the splint was removed, but were then not brought back despite their having further appointments. The family doctors of these children were contacted, and were satisfied that in each case the children had developed normally. Five mothers refused to allow their children to be splinted or to bring them to the clinic. They have not reappeared at the clinic with late deformities. The family doctors of these children have been contacted, and considered them to be normal. In contrast, there were eight children whose mothers originally adopted a similar attitude but brought them back for treatment when they realised there was something wrong. All these children required in-patient treatment.

Forty-one children moved to other parts of Scotland. Thirty families emigrated to England and a further eighteen families went overseas. This group $(2 \cdot 4$ per cent of the total) reflects the population drift from the rural areas of Scotland. 


\section{RESULTS}

Unsplinted group-Children who were clinically normal when they were seen at three weeks were not splinted, but they were followed until they were a year old. The main features in this group are shown in Table III. This serves as a baseline against which to compare the other groups. Girls predominated by six to four. There was a family history in 6 per cent, and there were other abnormalities in 1 per cent; 3 per cent were breech deliveries and 3 per cent were born by Caesarean section. The comparable figures for the region as a whole are 4 per cent breech births and 6 per cent Caesarean deliveries (MacGillivray 1970). In two-thirds the upper femoral epiphyses had not appeared by the age of three months (71 per cent of boys and 63 per cent of girls); in one out of ten they had still not appeared at the age of six months (11 per cent of boys and 8 per cent of girls). Over one-third were walking independently at the age of one year ( 32 per cent of boys and 43 per cent of girls). Delayed appearances of the epiphyses is not associated with late walking.

TABLE IV

Special Features of Operation Group

\begin{tabular}{|c|c|c|c|c|}
\hline \multirow[t]{2}{*}{ Features } & \multicolumn{2}{|c|}{$\begin{array}{c}\text { Operation group } \\
\text { Sex ratio } \\
6 \text { girls : } 1 \text { boy }\end{array}$} & \multicolumn{2}{|c|}{$\begin{array}{l}\text { Unstable group } \\
\text { Sex ratio } \\
6 \text { girls : } 4 \text { boys }\end{array}$} \\
\hline & Per cent & Boys : girls & Per cent & Boys : girls \\
\hline Family history & 12 & $23: 10$ & 5 & -- \\
\hline Other defects & 12 & $23: 10$ & 1 & -- \\
\hline Breech delivery & 6 & $0: 7$ & 4 & - \\
\hline Bilateral dislocation & 41 & $54: 37$ & 53 & $55: 51$ \\
\hline Left dislocation & 40 & $15: 44$ & 28 & $27: 29$ \\
\hline Right dislocation . & 19 & $31: 19$ & 19 & $18: 20$ \\
\hline
\end{tabular}

Group with limitation of abduction-When limitation of abduction of the hips was still present at three weeks we applied a splint and treated the child as if the hips were dislocated. We appreciate that in some and perhaps many of these children splintage is not necessary; nevertheless, the reasons for treating them are valid and are discussed later. The observations in this group are shown in Table III, and are similar to those in the unsplinted group. The condition was bilateral in 84 per cent, and the sex incidence was almost equal in these bilateral cases. This is in contrast to the sex incidence of the whole series and suggests that these bilateral cases probably include many boys who would have developed normally without treatment. Stiffness was still present at six weeks in 16 per cent, and this was commoner in boys than girls. Persistent stiffness was not associated with late walking, and none of these children subsequently showed signs of cerebral palsy.

Unstable group-Children whose hips were still unstable at three weeks were splinted, and the splints were kept on until the children were three months old. The findings in this group are shown in Table III. The general features are similar to those of the group with limited abduction, but in only 53 per cent was the instability bilateral, and in unilateral cases the left hip was more commonly affected than the right. Thirty-six per cent showed limitation of abduction as well as instability. Instability was still present in 13 per cent at six weeks and this was commoner in boys than in girls. Neither associated stiffness nor persistent instability was associated with late walking.

VOL. 54 B, NO. 1, FEBRUARY 1972 
TABLE V

Results of Examination Findings at Two Days and Three Weeks

\begin{tabular}{|c|c|c|c|c|c|c|c|c|c|c|c|c|}
\hline \multirow{3}{*}{$\begin{array}{l}\text { Condition } \\
\text { of hip }\end{array}$} & \multicolumn{3}{|c|}{ At two days } & \multicolumn{9}{|c|}{ At three weeks } \\
\hline & \multirow{2}{*}{ Boys } & \multirow{2}{*}{ Girls } & \multirow{2}{*}{ Total } & \multicolumn{3}{|c|}{ Normal } & \multicolumn{3}{|c|}{ Unstable } & \multicolumn{3}{|c|}{ Stiff } \\
\hline & & & & Boys & Girls & Total & Boys & Girls & Total & Boys & Girls & Total \\
\hline Unstable & 25 & 53 & 78 & 12 & 27 & 39 & 8 & 18 & 26 & 5 & 8 & 13 \\
\hline Stiff & 14 & 8 & 22 & 8 & 2 & 10 & - & 1 & 1 & 6 & 5 & 11 \\
\hline Total & 39 & 61 & 100 & 20 & 29 & 49 & 8 & 19 & 27 & 11 & 13 & 24 \\
\hline
\end{tabular}

Operation group-Eighty-six children needed operation. In most the diagnosis had been missed at birth, in some the condition had been diagnosed at birth. The reasons for this will be discussed later. The features of the operation group are shown in Table III; that they differ markedly from the other groups is shown in Table IV.

In the operation group the female preponderance was more marked; a family history was more common, especially in boys; associated abnormalities were also more common, particularly in boys; breech births were more common, and the incidence of these was higher than that for the region as a whole. In unilateral cases the left hip was the more commonly affected, especially in girls. Similar features are shown in many other series of operative cases in the literature, but the reasons for them are obscure.

Results of examination at two days and three weeks-The differences between the first examination at two days and the second examination at three weeks are shown in Table V. At the first examination, of every 100 infants who were abnormal, seventy-eight had instability of the hips, and the other twenty-two had limitation of abduction only (Fig. 3); the relative rarity of stiffness is more marked in girls than in boys.
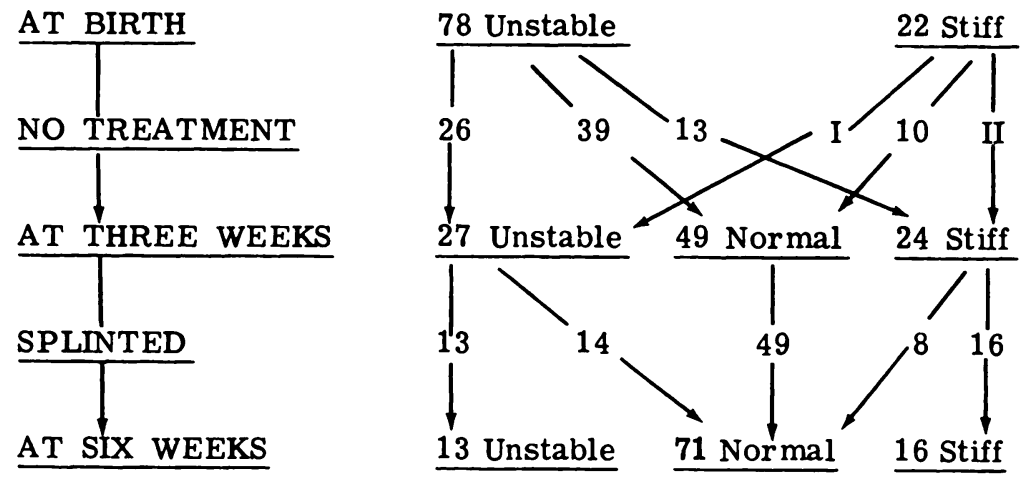

Fig. 8

The fate of every hundred hips abnormal at birth.

The findings at the second examination were the same as those at the first examination in only 27 per cent, a surprisingly low figure. Almost half the hips were normal at the second examination; this spontaneous cure is commoner in girls than in boys. More than a quarter were still unstable, and these also included more girls than boys. The remainder of the abnormal hips still showed restricted abduction, but these were not necessarily the same hips that were affected initially. Thirteen of the seventy-eight originally unstable hips showed only restricted abduction after three weeks. More important are the few (6 per cent) originally stiff hips which later show definite instability. 


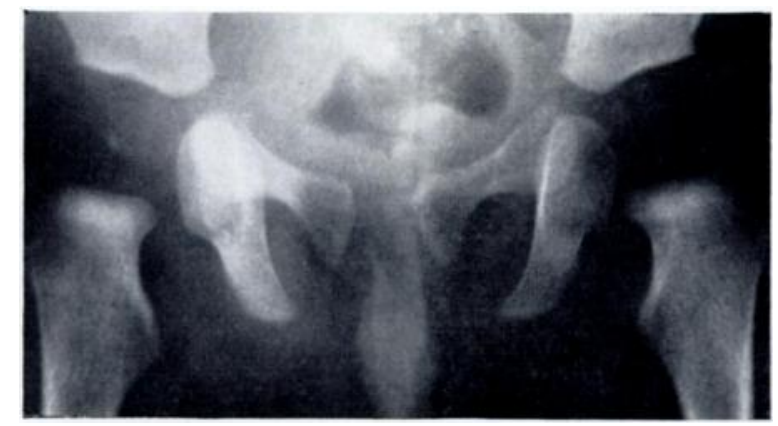

Fig. 9

Absent left epiphysis in a boy treated for left-sided instability.

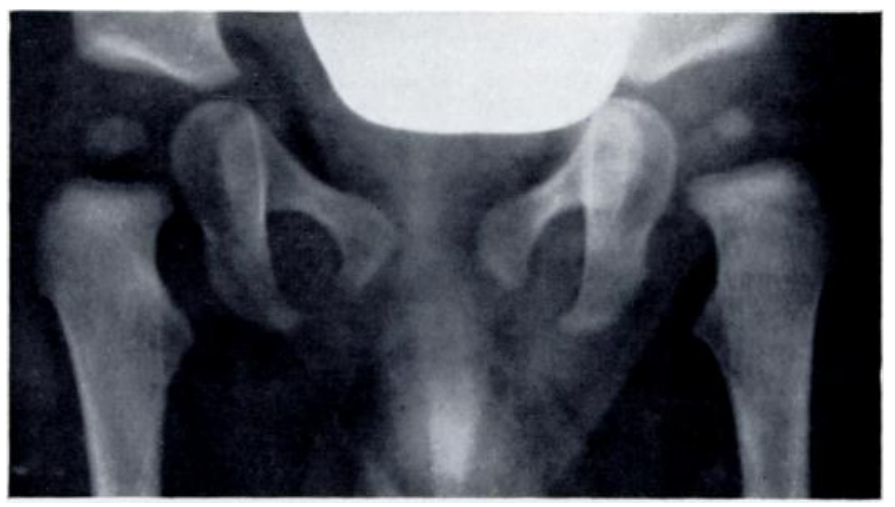

Fig. 10

Small left epiphysis in a girl treated for left-sided instability.

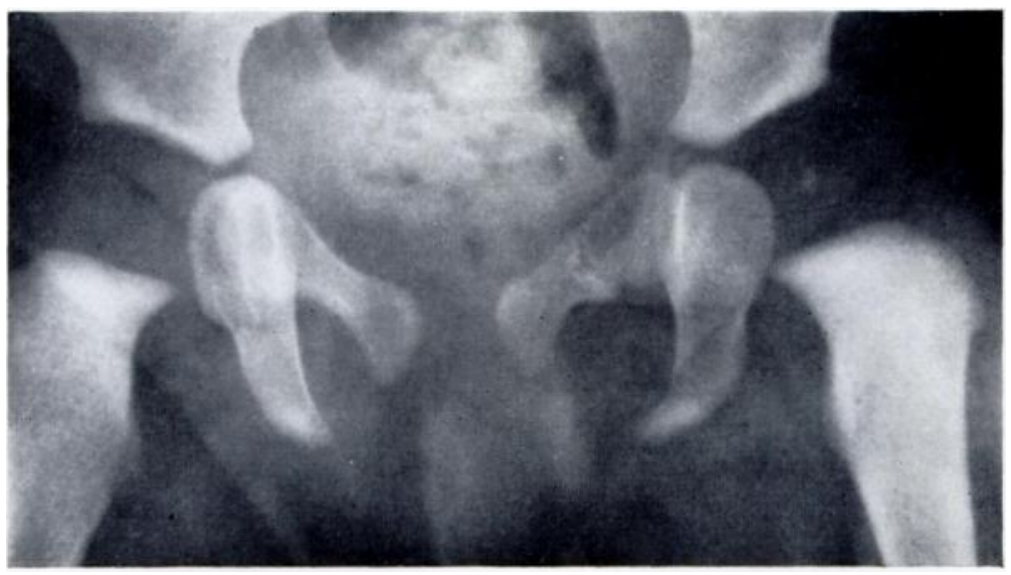

Fig. 11

Epiphysis appearing on the abnormal side before the normal side. 
Barlow (1968) emphasised that limitation of abduction may prevent the demonstration of instability and thus mask dislocation. We have found that 37 per cent of hips found to be clinically stiff but not unstable had a positive Andrén-von Rosen radiograph (Table II); one can therefore not neglect hips that are merely stiff. Barlow (1968) advised adductor tenotomy under general anaesthetic as a diagnostic aid in these cases. We splint all persistently stiff hips, preferring unnecessary splintage to unnecessary anaesthesia.

Congenital dislocation of the hin mav thus nresent as either instability or as limitation of

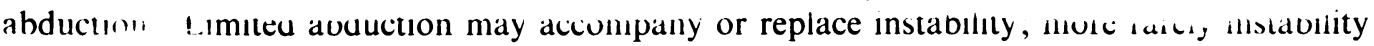
may replace stiffness. There is a high spontaneous cure rate, but the crux of the matter is that we do not know how to distinguish hips that will recover spontaneously from hips that require treatment, and until we do, any abnormality still present at three weeks is an indication to apply a splint.

After three weeks in a splint only twenty-nine out of 100 hips will still be abnormal, and more of these will be stiff than unstable. The fate of every 100 abnormal hips is shown in diagrammatic form in Figure 8.

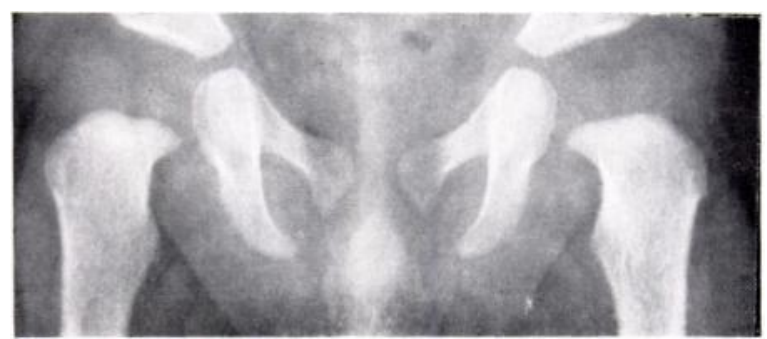

FIG. 12

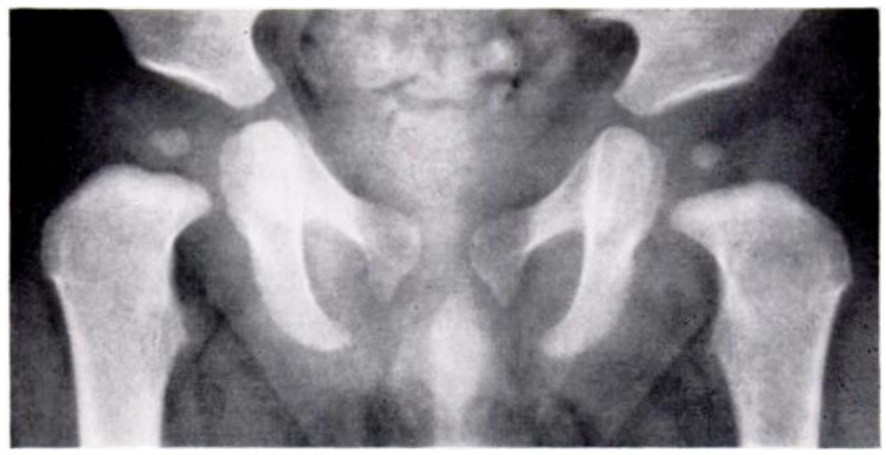

Fig. 13

Figure 12-Absent epiphyses in a boy aged 1 year who had unstable hips at birth. Figure 13-Radiograph of the same child at 15 months.

The side affected-The side affected at different ages varies in a puzzling way. This is shown in Table VI. At birth the condition is usually bilateral; when only one hip is involved, it is more often the left than the right. At three weeks, however, rather more left hips have become normal than either right hips or bilaterally affected hips. By six weeks 87 per cent are normal, and the numbers are the same regardless of side. In missed cases, bilateral involvement is again most common, followed closely by left-sided involvement which is then even more common than it was at birth.

Development of the upper femoral epiphyses-Delayed appearance of the upper femoral epiphysis has been thought to be a sign of congenital dislocation, but this is not an invariable or a reliable sign. We have found that 66 per cent of untreated children have no epiphysial centre 
at three months, and 11 per cent have no epiphysial centre at six months: the figures are higher for boys than girls. Not only does the time of appearance vary in different children, but it may vary between the two hips in the same child, and the epiphyses may then remain different in size for several months. Such delay is usually thought to occur on the unstable or dislocated side; an example of this is Figure 9, in which no epiphysis is seen on the left side in the six-month radiograph of a boy who had been treated for left-sided instability. Figure 10 shows a small epiphysis on the left side in the six-month radiograph of a girl who has been treated for left-sided instability. Sometimes, however, the normal side is the slower to develop, and this may occur

TABLE VI

The Side Affected in UnStable Hips

\begin{tabular}{|lcccc|}
\hline & $\begin{array}{c}\text { Bilateral } \\
(\text { per cent })\end{array}$ & $\begin{array}{c}\text { Left } \\
\text { (per cent) }\end{array}$ & $\begin{array}{c}\text { Right } \\
(\text { per cent })\end{array}$ \\
\hline At birth & 46 & 35 & 19 \\
Normal at three weeks & 47 & 56 & 47 \\
Normal at six weeks & 87 & 87 & 87 \\
Operation group & 41 & 40 & 19 \\
\hline
\end{tabular}

in untreated as well as in splinted hips. Figure 11 shows the six-month radiograph of a girl who had instability of the left hip at birth. By three weeks the hip was clinically normal and no splint was applied; the radiograph shows that the epiphysis first to appear was that of the abnormal side.

Both epiphyses are normally clearly visible by a year. In only two children in this series was there delay beyond this time. Both were boys born with unstable hips which were splinted at three weeks. They were clinically normal at six weeks, and the splints were removed at three months. Neither child was walking at a year, but their subsequent progress was normal. Figure 12 shows the radiograph of one of these children at twelve months, and Figure 13 the appearances at fifteen months.

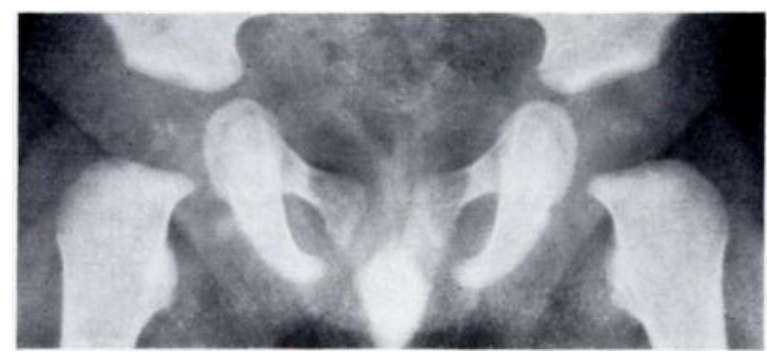

Fig. 14

Double ossific centres.

In a few cases we have been concerned because the radiographs at one year show apparent coxa valga despite correct radiographic positioning. This was always in children who were not then walking, and it corrected rapidly. The appearance can of course be produced if the hips are not in neutral rotation when the radiograph is exposed.

Several children in both treated and untreated groups showed fluffiness or irregularity of the epiphyses. This is because the femoral head may develop from more than one ossific centre, and the appearance is of no clinical significance. Figure 14 shows it in the six-month radiograph of a boy who was treated for bilateral instability.

VOL. 54 B, NO. 1, FEBRUARY 1972 


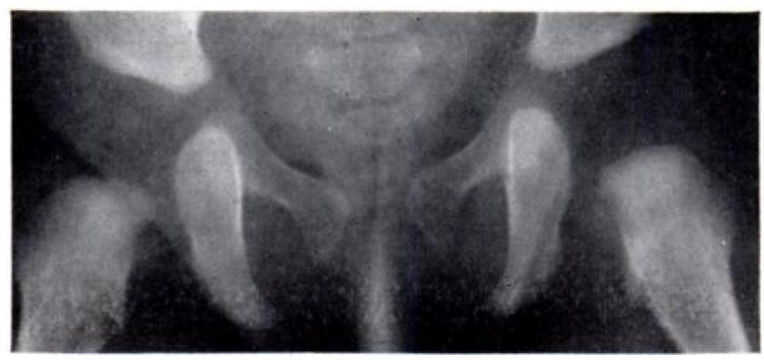

FIG. 15

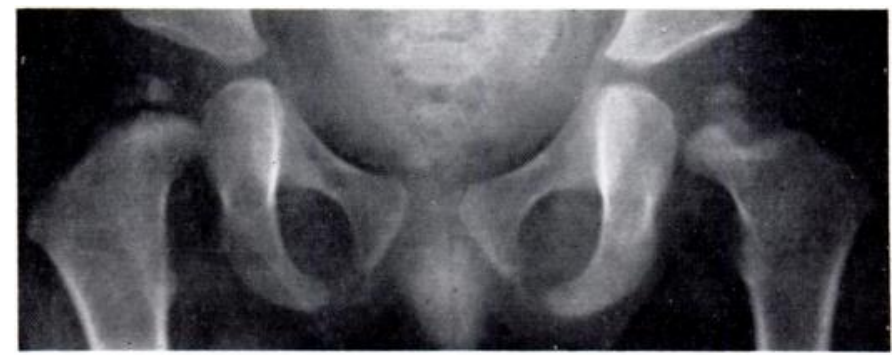

FIG. 16

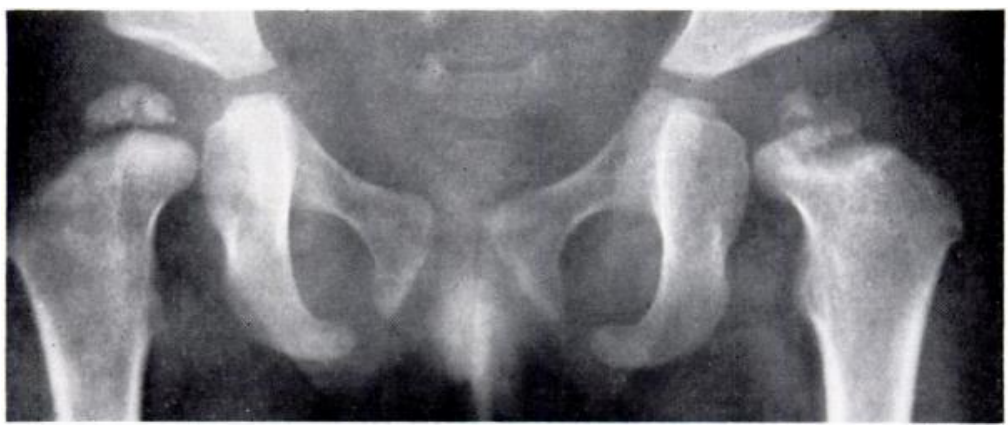

FIG. 17

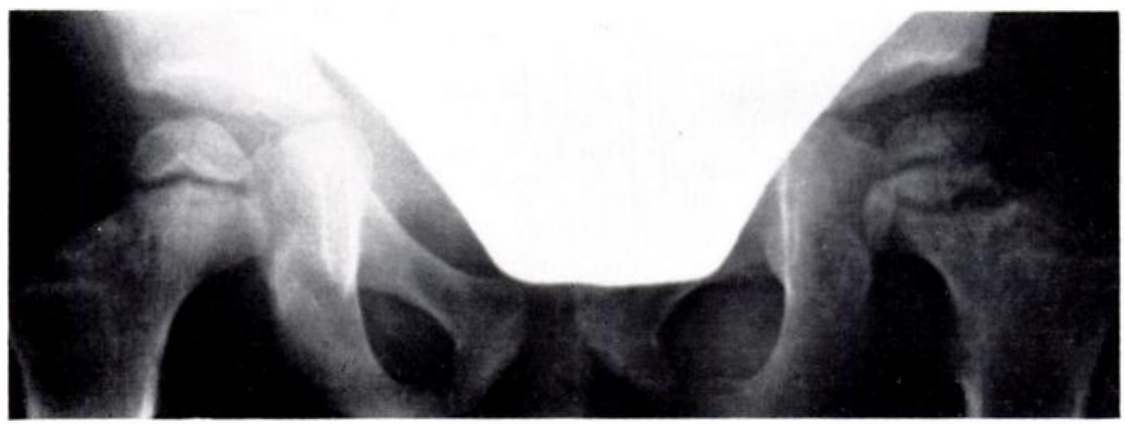

Fig. 18

Figure 15-Radiograph showing epiphyses absent at 3 months. Figure 16-Radiograph of the same child at 15 months - note the epiphysial and metaphysial changes. Figure $17-$ Radiograph of the same child at 22 months. Figure $18-$ Radiograph of the same child at 3 years. 
It has been suggested that splinting an infant's hips in abduction may be positively harmful and may lead to avascular necrosis. This must be considered very carefully if one is admittedly treating some children who would recover without treatment, but there is only one case in this series that has caused any anxiety. The radiographs are bizarre, and we are not certain of their significance. They may represent avascular changes, which, in turn, may have been produced by the splint. The left hip in this girl was noted to be unstable at birth, and this finding was confirmed at three weeks when a splint was applied. The splint was kept on until the child was three months old, when the radiograph (Fig. 15) showed no femoral epiphyses. The epiphyses were still absent at six months, but were present at a year although the child was not walking. Figure 16 shows the appearance at fifteen months, by which time the child was walking; the hips appeared clinically normal and there was no sign of any other abnormality or disease. Figure 17 shows the appearance at twenty-two months, and Figure 18 the appearance at thirty-eight months: on the left side there is a large "mushroom" femoral head which in patients who have undergone operation we have come to associate with widespread avascular necrosis; on the right side there is flattening of the medial side of the femoral head which in operation cases we have come to associate with localised avascular changes. Although the radiographic changes are striking, the child remained symptom-free throughout, the hips appeared clinically normal and there was never any sign of muscle spasm or limitation of movement.

\section{ANALYSIS OF FAILURES}

Eighty-six children, 5 per cent of the total, required in-patient treatment. It is important, and salutary, to examine the reasons for this. It has been suggested (Mercer 1959) that dislocation may not always be present at birth, and may occasionally occur when the hips are first extended; we know of no evidence to support this.

It is possible that the method of splintage was not effective, or that it was applied too late. We have had no failures in cases in which the splint has been properly used. We have tried to reduce the number of children splinted unnecessarily, and do not now apply the splints until the children are three weeks old. The latest time that splintage can be successful is uncertain: we have had one success when the delay was as long as nine weeks, and several failures when it was as short as six weeks. We have had no failures when the splints were fitted at three or four weeks and retained until the children were three months old. Stanisavljevic (1964) found that if treatment was delayed longer than four weeks it had to be continued for five to eleven months before the hips were normal.

In the early stages of the study we treated all children as soon as the diagnosis was made: splints were applied to alternate infants, and the others were treated with double nappies. All were re-examined at three weeks. Only 24 per cent of those treated with nappies were then normal compared with 72 per cent of those treated by splintage. The cure rate of those who were splinted is higher than the spontaneous cure rate, but many were splinted unnecessarily, and those who had been splinted but who were still unstable at three weeks became stable no quicker than those who were splinted for the first time at three weeks. Double nappies are an inefficient form of splintage, and we agree with Finlay et al. (1967) that they give a false sense of security and should not be used.

Eight children needed operation because the splints were left off too early. When examined at three months the hips were passed as normal although the notes in all cases record that there was still a little stiffness. Clearly, any limitation of abduction at three months necessitates further review. The radiographs at this age are difficult to interpret if the femoral epiphyses have not appeared. Careful attention should be paid to Shenton's line, Perkins's line, the slope of the acetabulum and the presence of an indentation or notch at the acetabular margin.

Figure 19 shows the three-month radiograph of a girl who had been treated for instability of the left hip. No significant clinical abnormality was noted, and the splint was left off; the 
radiograph at six months (Fig. 20) shows that the left hip is subluxated and also shows an acetabular notch; a small notch is also visible in Figure 19.

Figure 21 shows the three-month radiograph of a girl who had been treated for instability of both hips; no clinical abnormality was noted, and the splint was left off; the radiograph at six months (Fig. 22) showed that another mistake had been made. Acetabular notches are visible in both films.

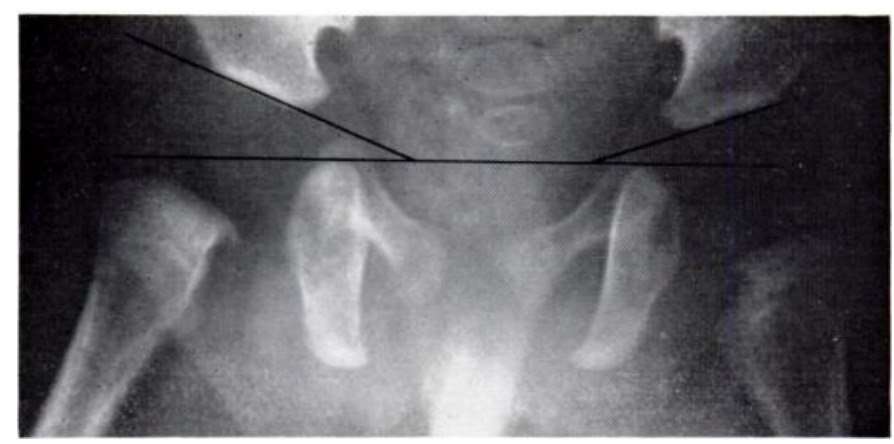

FIG. 19

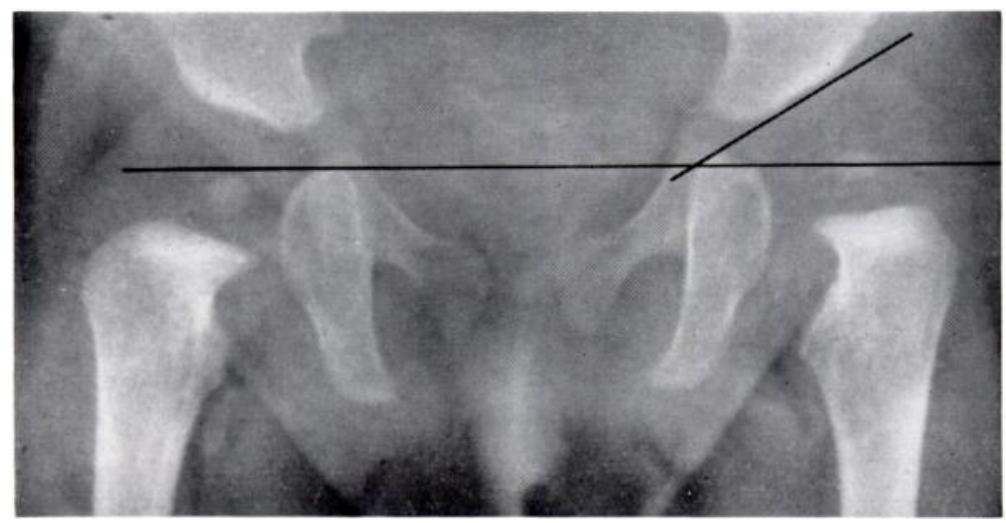

Fig. 20

Figure 19-Radiograph at 3 months; left hip unstable at birth. Figure 20Radiograph of the same child at 6 months.

The acetabular notch should be looked for specially in all three-month radiographs, but it may even be seen in neonatal films (Fig. 2) and is well shown in Figure 23 which is the three-month radiograph of a subluxed hip in a girl who had instability of the left hip at birth; at three weeks it was as normal and at three months there was severe limitation of abduction of the left hip. When we first observed this radiological sign we could find no reference to it in the literature, but a description has since been published by Doberti and Manhood (1968).

A child may not be seen by the same doctor at each visit. Some are seen by surgeons in training, who must be allowed responsibility, and it is inevitable that an occasional mistake will be made. But no great harm will ensue if a strict rule is made that no child is discharged until the femoral epiphyses are present and seen to be in normal position.

Eight other children needed operation because the mothers were not convinced that treatment was really necessary and had either refused treatment or removed the splints when they got home; the children were brought back for treatment when the mothers realised their mistake. The hips of the six girls and two boys were all unstable initially. Five other children, whose mothers refused to cooperate, developed normally; three girls had instability, and one 


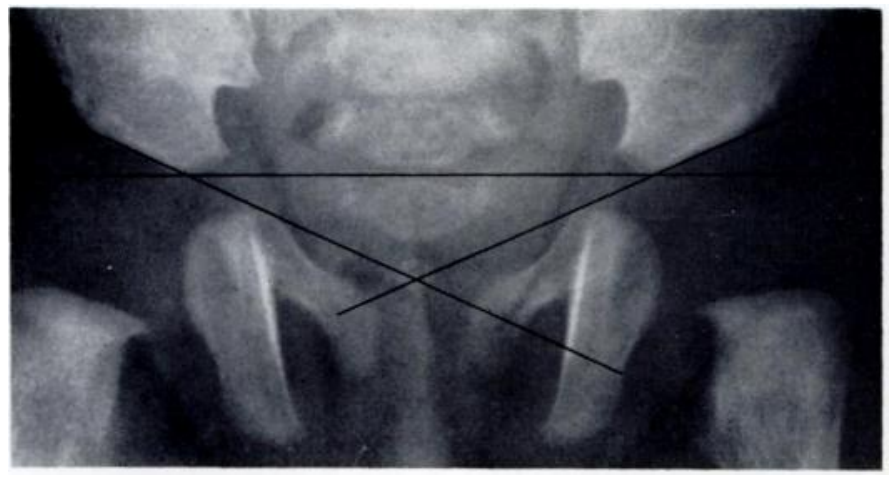

FIG. 21

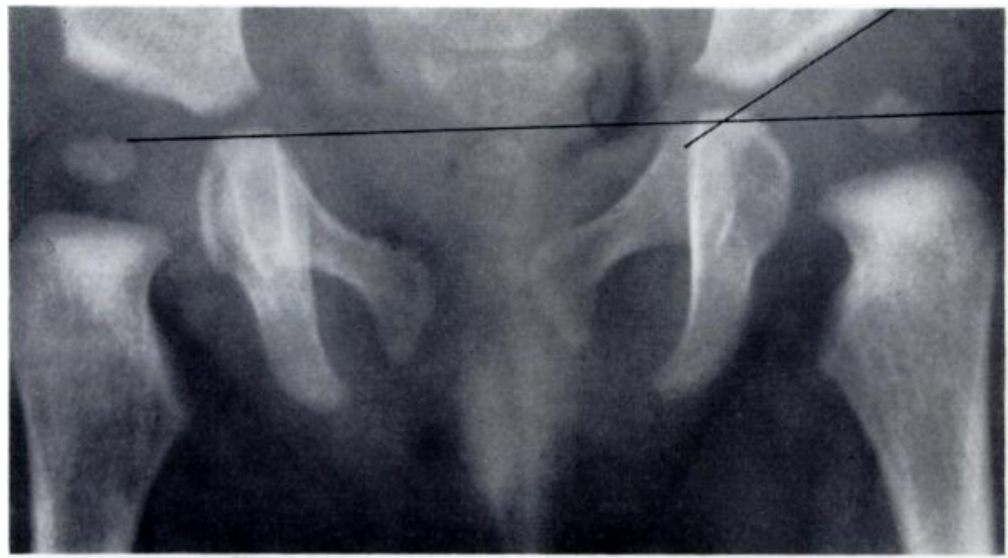

FIG. 22

Figure 21-Radiograph at 3 months; both hips unstable at birth. Figure 22Radiograph of the same child at 6 months.

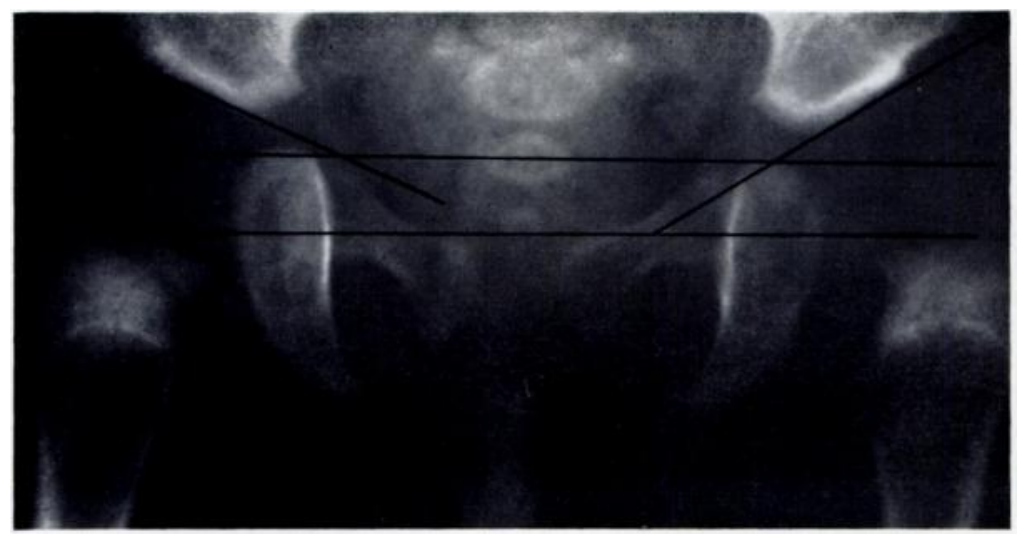

FIG. 23

Radiograph at 3 months showing left dislocation and a well-marked acetabular notch.

VOI. 54 B, NO. 1, HERUUARY 1972 
boy and one girl had limitation of abduction. Refusal of treatment gives two out of three chances that the child will suffer, but the chance is slightly less if the child has a stiff rather than an unstable hip.

Why should a mother refuse treatment? No mother readily accepts the fact that her child is deformed. If she can see the deformity, as in the case of club foot, she will cooperate with treatment, and is grateful for what is being done. When her child has a congenital dislocation of the hip she herself can see nothing wrong, and may resent the suggestion that her baby is not perfect. It is essential that the doctor who makes the diagnosis must explain the situation and reassure the mother. Refusal occurs in all social groups, and may be associated with post-natal depression. Another difficulty occurs if spontaneous recovery has not occurred and the mother is perplexed that treatment was not started at once. These problems seldom arise if the fathers also attend, so this is encouraged. Difficulty in obtaining cooperation is especially likely if the child is illegitimate.

The concentration of the children in one clinic is helpful because the mothers discuss their children and the treatment, and a mother who has defaulted and whose child has subsequently needed operation is a powerful ally in persuading the doubtful to accept advice.

The sixteen failures, half from stopping treatment too soon and half from refusal of treatment, account for only 19 per cent of the children who needed operation. In the other seventy the diagnosis was missed at birth. Table VII shows the place of birth of these children and the numbers of missed diagnoses in each hospital.

TABLE VII

Place of Birth of Missed Cases

\begin{tabular}{|c|c|c|c|c|}
\hline \multirow{2}{*}{\multicolumn{2}{|c|}{ Place of birth }} & \multirow{2}{*}{$\begin{array}{c}\text { Live births } \\
\text { (number) }\end{array}$} & \multicolumn{2}{|c|}{ Missed cases } \\
\hline & & & (number) & (per thousand) \\
\hline \multicolumn{2}{|c|}{ Aberdeen Maternity Hospital } & 28,426 & 30 & $*_{1}^{*} .06$ \\
\hline \multicolumn{2}{|c|}{ Other Aberdeen hospitals } & 14,187 & 16 & $1 \cdot 13$ \\
\hline Fonthill & . & 6,353 & 8 & $1 \cdot 26$ \\
\hline Queen's Cross & . & 4,837 & 5 & $1 \cdot 04$ \\
\hline Summerfield & . & 2,997 & 3 & $1 \cdot 00$ \\
\hline Peripheral . & . & 30,104 & 15 & $* 0 \cdot 50$ \\
\hline At home & . & 3,958 & 9 & $* 2 \cdot 28$ \\
\hline Regional total & . & 76,675 & 86 & $1 \cdot 12$ \\
\hline
\end{tabular}

Nine peripheral hospitals with a combined total of 10,918 live births missed no cases. * The differences in the rate of missed cases in those children born in the Aberdeen Maternity Hospital, those born in peripheral hospitals, and those born at home are statistically significant.

For the region as a whole there were $1 \cdot 12$ missed cases per 1,000 live births. Few children ( 5 per cent) were born at home, but these are the most likely to escape post-natal examination, and the number of missed cases in this group was twice the regional figure $(2.28$ per 1,000 live births).

The central hospital with ample staff would be expected to have the best results, but this was not so. The number of missed cases in the Aberdeen Maternity Hospital was about the same as the regional figure ( 1.06 per 1,000 live births) but the figures for the other hospitals in Aberdeen were not quite so good ( $1 \cdot 13$ per 1,000 live births). The difference is not statistically significant. 
The best results were in the peripheral hospitals where the failure rate was only 0.5 per 1,000. Forty per cent of children in the region are born in these hospitals which are staffed by family doctors, one of whom usually takes on the responsibility of examining all infants for congenital deformities. Such doctors have become confident in the method of examination, and in nine peripheral hospitals with a combined total of 10,918 live births there has been no missed case.

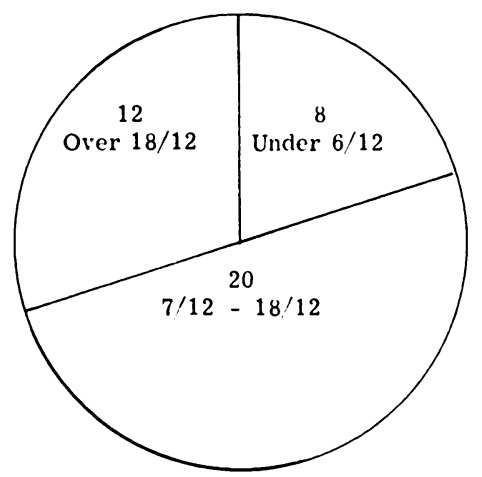

40 Missed $1960-64$

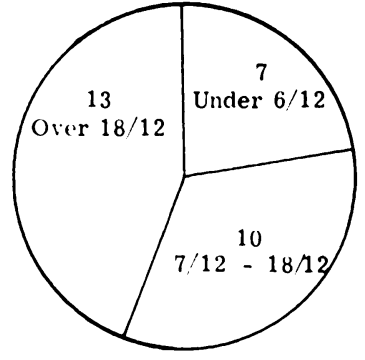

30 Missed 1965-69

FIG. 24

Cases missed at birth; 1960-64 compared with 1965-69.

Although, as a region, we have failed in our aim to diagnose all cases of congenital dislocation of the hip in the neonatal period and thus to avoid the need for operation, our results for 1965 to 1969 were better than those for 1960 to 1964 (Fig. 24). However, it is disturbing that so many missed at birth were not referred for treatment until they were over eighteen months of age, despite being seen by health visitors or at the Local Authority Health Clinics. Associated defects-Other congenital abnormalities were present in 2 per cent of children with abnormal hips; they were more common with a family history of hip disease. The defects were very varied, and only two occurred with any frequency. Familial joint laxity occurred in five children, four in the same family; the treatment of the hips in these children presented no special difficulty. Five other children-all girls-had genu recurvatum; this is not a common congenital abnormality, and they were the only examples of the condition that we have seen during the ten years under review; the association with unstable hips must be more than fortuitous. The clinical features of these cases are summarised in Table VIII. The knee deformity was treated by anterior plaster splints with the knees in 60 degrees of flexion and presented no problems, all being normal by eight weeks and remaining so. In contrast, three needed operation for the hips, perhaps because more attention was paid to the obvious knee deformities than to the hips. It would perhaps have been better to immobilise the hips as well as the knees in plaster.

Cost of treatment-The cost of treating an individual child was estimated in 1965 from figures supplied by the Regional Hospital Board. Clearly, the greater the cost the more trouble there is for the child and parent.

The cost of treating a child who requires only splintage is under $£ 5$ (Table IX). With admission to hospital and operation the costs escalate rapidly, and although depending on time in hospital, number of operations and length of follow-up, the cost is never less than $£ 250$ and often over $£ 1,000$.

\section{DISCUSSION}

Etiology - The cause of the condition is still unknown, and there is almost certainly more than one factor involved. Our failure to eliminate the need for operative treatment, even though we splint some hips unnecessarily, has made us reconsider the various theories to see if there

VOL. 54 B, NO. 1, FEBRUARY 1972 
is any clue as to how one could distinguish those children at special risk from the vast majority in whom spontaneous recovery will occur.

Studies of twins suggest there are both genetic and environmental causes (Human Genetics 1967); the concordance rate for uniovular twins is 42.7 per cent and for binovular twins $2 \cdot 8$ per cent. The approximate risk for sons and brothers is one in a hundred, and for daughters and sisters one in fifteen.

The condition is not uncommon after Caesarean delivery, and is therefore not associated with the process of birth. McKibbin (1970) has shown that laxity of the capsule is the most

TABLE VIII

Clinical Features of the Five Girls with Genu Recurvatum

\begin{tabular}{|c|c|c|c|c|c|c|}
\hline & & Case 1 & Case 2 & Case 3 & Case 4 & Case 5 \\
\hline Genu recurvatum & . & Right & Both & Both & Right & Left \\
\hline \multicolumn{2}{|c|}{ Palpable jerk during flexion } & - & : & . & -. & - \\
\hline Foot deformity & $\cdot$ & $\begin{array}{c}\text { Both } \\
\text { calcaneo-valgus }\end{array}$ & $\begin{array}{c}\text { Both } \\
\text { calcaneo-valgus }\end{array}$ & $\ldots$ & $\begin{array}{c}\text { Left } \\
\text { metatarsus varus }\end{array}$ & \\
\hline Family history & . & 一 & - & - & & -- \\
\hline Presentation & . & Breech & Vertex & Breech & Vertex & Breech \\
\hline Hip abnormality. & . & Both unstablc & Both unstable & Left unstable & Both unstable & Left stiff \\
\hline No epiphyses at three & months & : & $:$ & $\cdots$ & : & \\
\hline No epiphyses at six $r$ & honths & . & & & & 一 \\
\hline Walking at one year & . & . & $\cdots$ & - & $\cdots$ & - \\
\hline Operation needed & . & . & $\cdots$ & : & - & + \\
\hline Reason & . & $\begin{array}{l}\text { Splinted } \\
\text { late }\end{array}$ & $\cdots$ & $\begin{array}{l}\text { Mother } \\
\text { defaulted }\end{array}$ & - & $\begin{array}{c}\text { Splinted } \\
\text { late }\end{array}$ \\
\hline
\end{tabular}

TABLE IX

Basic Cost of Treatment Using the Splint

One splint : each child needs more than one splint, but each splint can be renovated and re-used

Five out-patient attendances at $42 p$; visits at three weeks, six weeks, three months, six months and one year . . . . . . . $\quad £ 2.10$

Three radiographs at $40 \mathrm{p}$; films at three months, six months and one year $\quad £ 1.20$

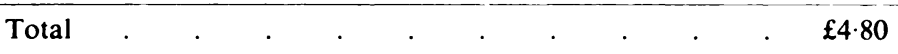

striking anatomical abnormality. Such laxity occurs in familial joint laxity; Andrén and Borglin (1960) suggested that it could also be produced by a disorder of oestrogen metabolism; their work has not been confirmed by Aarskog, Støa and Thorsen (1966), nor by Thieme, Wynne-Davies, Blair, Bell and Loraine (1968). Barlow (1962) has shown that the incidence is lower than expected in children with a birth weight of under 1.2 kilograms, possibly because they are born before the joint laxity develops; this was confirmed for the cases in this series by Frew (1966).

Wilkinson (1966) has shown that breech malposition in utero is also a factor. Frew (1966) found that in unilateral dislocations the side affected was not related to the side nearest the 
mother's back at the time of delivery. A seasonal variation has been reported, and Frew found some evidence that the incidence was low during the spring months (Table $\mathrm{X}$ ).

McKibbin (1970) has made some interesting observations on the factors which may lead to instability of the infant hip; he has shown that in newborn infants (with normal hips) the anteversion of the femoral neck and the anteversion of the acetabulum both vary, but there is no apparent correlation between the two; high acetabular anteversion is not necessarily associated with low femoral anteversion; the sum of the two figures gives some idea of the inherent instability of the hip, and he has called this the instability index. Mean values for neonatal males are: acetabular anteversion 6 degrees + femoral anteversion 26 degrees $=$ instability index 32; mean values for neonatal females are: acetabular anteversion 9 degrees + femoral anteversion 32 degrees $=$ instability index 41 .

TABLE X

SEASONAL INCIDENCE OF INSTABILITY

\begin{tabular}{|ccc|}
\hline Season & Months & $\begin{array}{c}\text { Incidence } \\
\text { (per cent })\end{array}$ \\
\cline { 1 - 2 } Spring & March, April, May & 0.99 \\
Summer & June, July, August & 3.66 \\
Autumn & September, October, November & 2.44 \\
Winter & December, January, February & 3.24 \\
\hline
\end{tabular}

TABLE XI

INCIDENCE OF Hip AbNORMAlities IN THE NeWBorN

\begin{tabular}{|c|c|c|c|c|}
\hline \multicolumn{2}{|l|}{ Series } & Abnormal hips & Total examined & Per thousand \\
\hline Palmén (1961) & . & 70 & 12,394 & $5 \cdot 65$ \\
\hline Von Rosen (1962) & . & 68 & 31,200 & $2 \cdot 18$ \\
\hline Barlow (1962) & . & 139 & 9,289 & 14.97 \\
\hline Stanisavljevic (1964) & . & 29 & 6,000 & $4 \cdot 84$ \\
\hline Weissman and Salam & a (1966) & 45 & 16,841 & $2 \cdot 68$ \\
\hline Smaill (1968) & . & 24 & 6,000 & 4.00 \\
\hline Aberdeen (1970) & . & 1,671 & 76,675 & $21 \cdot 80$ \\
\hline
\end{tabular}

The incidence in Aberdeen is about one per fifty live births.

The higher instability index in girls may explain the sex incidence in persisting dislocations. McKibbin (1971) could find no significant difference in the instability index between the two sides, but the numbers of pelves that he examined were small and it is possible that differences may arise from time to time and may explain the relative frequency of left-sided involvement in unilateral cases.

McKibbin suggests that the upper limit of normal of the instability index is in the region of 60. If one could devise reliable radiological methods of measuring femoral and acetabular anteversion in infants, one might be able to pick out some infants who are at special risk.

Incidence-The true incidence of abnormality of the hips at birth is difficult to determine, and it varies widely in the literature (Table XI); this may be explained by examination at different ages, and Barlow (1962) has shown that there is a high spontaneous cure rate even within the 
first week; von Rosen (1968) thought that the annual incidence varied widely, and it is well known that the incidence varies in different parts of the world. In Aberdeen, where the children are examined within forty-eight hours of birth, the incidence of suspected abnormality is about one per fifty live births.

Sex differences-The hip in boys develops slower than in girls, and more girls than boys have epiphysial centres radiologically visible at three and six months, and more girls are walking independently at the age of a year than are boys.

Some abnormality of the hips at birth was more common in girls than boys, the ratio being about six to four; however, spontaneous correction was also more common in girls, and by six weeks the ratio of those still abnormal was about five to four: some unknown factor then came into play, and the ratio again rose and girls needed operation six times more often than boys.

In children who have open reduction a family history of hip disease and other associated congenital abnormalities was not only more common than in the whole series but also more common in boys, which suggests that a genetic factor may be the cause. The left hip was involved in children needing operation more than the right, and was commoner in girls: there may be an anatomical explanation for this.

Side differences-Bilateral involvement was more common than unilateral in all groups, but when one side was involved it was more often the left than the right. At birth the ratio of left to right hips was thirty-five to nineteen, the spontaneous cure rate was higher on the left than the right, and by three weeks the ratio of those remaining abnormal was fifty-six to forty-seven; by six weeks the figures were equal, and 87 per cent of unilateral and bilateral hips were normal. For some reason, in resistant hips requiring operative treatment the left side was again much more commonly involved, the ratio being forty to nineteen.

\section{SUMMARY AND CONCI.USIONS}

1. A scheme was started in 1960 with the object of ensuring that the hips of all babies born in the North-Eastern Region of Scotland were examined shortly after birth.

2. 1,671 children with suspected abnormalities have been seen during the ensuing ten years, and the findings are discussed.

3. Clinical examination is essential. Radiographic examination of the newborn is not necessary and may be misleading, but it does prove that some hips with limited abduction but no instability are in fact dislocated.

4. Treatment is not started when the diagnosis is made shortly after birth. The children are re-examined at three weeks, when spontaneous recovery has occurred in about half. The others, whether they show instability or only limitation of abduction of the hips, are treated in a simple splint until they are three months old. Any residual stiffness is an indication for further splintage.

5. The first radiographs are taken when the children are three months old, and no child is discharged until the radiographs show that the upper femoral epiphyses have appeared and are in normal position.

6. We appreciate that we are treating some children who would have recovered spontaneously, but we do not know how to distinguish them. There is no evidence that splintage harms a hip.

7. Eighty-six children ( 5 per cent of the total) needed operation usually because the diagnosis was missed at birth.

8. Children with familial joint laxity or genu recurvatum should be examined especially carefully for associated hip abnormality.

9. The incidence of abnormality of the hips at birth is about one in fifty live births.

I would like to thank the many orthopaedic and paediatric registrars who have worked with me during the period of this survey; without their enthusiastic cooperation this study would not have been possible. 


\section{REFERENCES}

Aarskog, D., Støa, K. F., and Thorsen, T. (1966): Urinary Oestrogen Excretion in Newborn Infants with Congenital Dysplasia of the Hip Joint. Acta Paediatrica Scandinavica, 55, 394.

ANDRÉn, L., and Borglin, N. E. (1960): A Disorder of Oestrogen Metabolism as a Causal Factor of Congenital Dislocation of the Hip. Acta Orthopaedica Scandinavica, 30, 169.

ANDRÉn, L., and Rosen, S. von (1958): The Diagnosis of Dislocation of the Hip in Newborns and the Primary Results of Immediate Treatment. Acta Radiologica, 49, 89.

Barlow, T. G. (1962): Early Diagnosis and Treatment of Congenital Dislocation of the Hip. Journal of Bone and Joint Surgery, 44-B, 292.

Barlow, T. G. (1968): Congenital Dislocation of the Hip. Hospital Medicine, 2, 571.

BEGG, D. (1960): Personal communication.

Doberti, A., and Manhood, J. (1968): A New Radiological Sign for Early Diagnosis of Congenital Hip Dysplasia. Annales de Radiologie, 11, R276.

Finlay, H. V. L., Maudsley, R. H., and Busfield, P. I. (1967): Dislocatable Hip and Dislocated Hip in the Newborn Infant. British Medical Journal, 4, 377.

Frew, E. (1966): Personal communication.

General Register OfFice (1961): Census of Scotland. Edinburgh: H.M.S.O.

Hiertonn, T., and James, U. (1968): Congenital Dislocation of the Hip. Journal of Bone and Joint Surgery, 50-B, 542.

Human Genetics (1967): Memorandum prepared by the Standing Medical Advisory Committee for the Central Health Services Council and the Secretary of State for Social Services. London: Ministry of Health.

MacGillivray, I. (1970): Personal communication.

McKibirn, B. (1970): Anatomical Factors in the Stability of the Hip Joint in the Newborn. Journal of Bone and Joint Surgery, 52-B, 148.

MCKibin, B. (1971) Personal communication.

Mercer, W. (1959): Orthopaedic Surgery. Fifth edition. London: Edward Arnold (Publishers) Ltd.

Ortolani, M. (1937): Un segno poco noto e sua importanza per la diagnosi precoce di prelussazione congenita dell'anca. La Pediatria, 45, 129.

Palmén, K. (1961): Preluxation of the Hip Joint. Acta Paediatrica, 50, Supplement 129.

PutTI, V. (1927): Per la cura precoce della lussazione congenita dell'anca. Archivio italiano di chirurgia, 18, 653.

Rosen, S. von (1962): Diagnosis and Treatment of Congenital Dislocation of the Hip Joint in the Newborn. Journal of Bone and Joint Surgery, 44-B, 284.

Rosen, S. von (1968): Further Experience with Congenital Dislocation of the Hip in the Newborn. Journal of Bone and Joint Surgery, 50-B, 538.

ROSER, W. (1879): Ueber angeborene Hüftverrenkung. Langenbecks Archiv für klinische Chirurgie, $24,309$.

Smaill, G. B. (1968): Congenital Dislocation of the Hip in the Newborn. Journal of Bone and Joint Surgery, 50-B, 524.

Stanisavluevic, S. (1964): Diagnosis and Treatment of Congenital Hip Pathology in the Newborn. Baltimore: Williams and Wilkins Company.

Thieme, W. T., Wynne-Davies, R., Blair, H. A. F., Bell, E. T., and Loraine, J. A. (1968): Clinical Examination and Urinary Oestrogen Assays in Newborn Children with Congenital Dislocation of the Hip. Journal of Bone and Joint Surgery, 50-B, 546.

Weissman, S. L., and Salama, R. (1966): Treatment of Congenital Dislocation of the Hip in the Newborn Infant. Journal of Bone and Joint Surgery, 48-A, 1319.

Wilkinson, J. A. (1966): Breech Malposition and Intra-uterine Dislocations. Proceedings of the Royal Society of Medicine, 59, 1106. 